\title{
Aqueous extract of Psoralea corylifolia L. inhibits lipopolysaccharide-induced endothelial-mesenchymal transition via downregulation of the NF-кB-SNAIL signaling pathway
}

\author{
BOM JUNG ${ }^{1}$, EUN HYANG JANG ${ }^{1}$, DARONG HONG ${ }^{2}$, IN HYE CHO ${ }^{1}$, MIN-JU PARK ${ }^{1}$ and JONG-HO KIM ${ }^{1}$ \\ ${ }^{1}$ Department of Pharmacy and ${ }^{2}$ Department of Life and Nanopharmaceutical Science, Graduate School, \\ Kyung Hee University, Dongdaemun-gu, Seoul 130-701, Republic of Korea
}

Received May 15, 2015; Accepted June 26, 2015

DOI: $10.3892 /$ or.2015.4154

\begin{abstract}
The epithelial-mesenchymal transition (EMT) is a pivotal event in the invasion and metastasis of cancer cells. Psoralea corylifolia L. (PC) inhibits the proliferation of various cancer cells. However, its possible role in EMT has not been identified. In the present study, we examined the effects of an aqueous extract of Psoralea corylifolia L. (PCAE), a typical medicinal decoction, on the EMT. Lipopolysaccharide (LPS) induced EMT-like phenotypic changes, enhancing cell migration and invasion. However, PCAE markedly reduced the expression of the LPS-induced EMT markers, including $\mathrm{N}$-cadherin and vimentin, and increased the expression of $\beta$-catenin. PCAE also inhibited cell migration and invasion in vitro. The effects of PCAE on the LPS-induced EMT were mediated by the inactivation of the NF- $\mathrm{KB}-\mathrm{SNAIL}$ signaling pathway. The results provide new evidence that PCAE suppresses cancer cell invasion and migration by inhibiting EMT. Therefore, PCAE is a potentially effective dietary chemopreventive agent for malignant tumors since it inhibits metastasis.
\end{abstract}

\section{Introduction}

Cancer is the cause of $25 \%$ of mortalities in developed countries (1). The prognosis of patients with advanced cancer is associated with the degree of aggressive metastasis $(2,3)$. It is imperative to understand the mechanisms involved in the metastasis of cancer since there are limited effective therapies available once the cancer has spread (3-5). The process of cancer metastasis appears to be regulated by a

Correspondence to: Professor Jong-Ho Kim, Department of Pharmacy, Graduate School, Kyung Hee University, 26 Kyungheedae-ro, Dongdaemun-gu, Seoul 130-701, Republic of Korea

E-mail: jonghokim@khu.ac.kr

Key words: Psoralea corylifolia L., epithelial-mesenchymal transition, migration, invasion, $\mathrm{NF}-\kappa \mathrm{B}-$ Snail signaling variety of gene products, however, the precise mechanisms of tumor cell dissemination are poorly understood $(6,7)$. The epithelial-mesenchymal transition (EMT), which has been recognized for several decades as a fundamental process of embryogenesis, may be involved in many pathological processes, particularly cancer progression. During the EMT of cancer cells in situ, epithelial cell layers lose their polarity and their cell-cell contacts, and then undergo a marked remodeling of the cytoskeleton. The expression of proteins that promote cell-cell contact, such as E-cadherin and $\beta$-catenin, may be lost, and the cells may acquire mesenchymal markers, such as vimentin, fibronectin and $\mathrm{N}$-cadherin, enhancing their ability for cell migration and invasion, which are pivotal events in the initial step of metastasis. Therefore, investigators have focused on inhibiting the EMT of cancer cells as a new therapeutic strategy to prevent cancer metastasis.

Cancer chemoprevention using natural compounds, known as 'dietary chemoprevention', prevents or suppresses the development of cancer, and is attracting interest as a cancer therapy. Understanding the molecular mechanisms of dietary chemoprevention is important for the safe application of these compounds in populations of patients at a high risk of cancer, as well as the development of novel treatment regimens for cancer patients.

Psolarea corylifolia L. (PC), commonly known as 'Boh-Gol-Zhee' in Korea, is used in traditional Ayurvedic and Chinese medicine. Six compounds (bakuchiol, psoralen, isopsoralen, corylifolin, corylin and psoralidin) are the major components of PC extract, and they possess significant antibacterial, antifungal, antioxidant, antitumor, estrogenic and immunomodulatory properties (8). It has been reported that whole extracts of PC, in organic solvents such as methanol, ethanol and chloroform, inhibit the proliferation of cancer cells, although the mechanism of action remains to be elucidated (9-11).

In the present study, we hypothesized that an aqueous extract of Psoralea corylifolia L. (PCAE), a typical medicinal decoction, is an effective inhibitor of EMT during cancer progression, and may therefore be used as a dietary chemopreventive agent for malignant tumors. We reported that PCAE significantly inhibited the invasion and migration of various cancer cells during the LPS-induced EMT by downregulating 
the NF- $\mathrm{kB}$-SNAIL signaling pathway. We suggested that PCAE is an excellent candidate dietary chemoprevention agent for use against malignant tumors since it inhibits metastasis.

\section{Materials and methods}

Materials and reagents. The PC used in the present study was kindly supplied by Professor Jung-Hye Choi (Kyung Hee University). Aqueous extraction procedures were performed by boiling $100 \mathrm{~g} \mathrm{PC}$ in $500 \mathrm{ml}$ distilled water for $30 \mathrm{~min}$ and then filtering using Whatman filter paper no. 2 (Advantec, Tokyo, Japan). Subsequently, the filtrates were combined and evaporated under a vacuum and lyophilized with a freeze dryer (Ilshine Laboratory, Suwon, Korea). The dry residue was stored at $-20^{\circ} \mathrm{C}$. MDA-MB231 and SKOV-3 cells were maintained in Dulbecco's modified Eagle's medium (DMEM) supplemented with $10 \%$ fetal bovine serum (FBS) and $1 \%$ penicillin/streptomycin antibiotics. The antibodies NF- $\kappa B$ p65 subunit, $\beta$-actin and PCNA were purchased from Santa Cruz Biotechnology, Inc. (Santa Cruz, CA, USA). Snail was purchased from Cell Signalling Technology (Beverly, MA, USA), vimentin and $\beta$-catenin were purchased from Abcam (Cambridge, MA, USA) and N-cadherin was purchased from BD Biosciences (San Jose, CA, USA).

Proliferation assay. Proliferation assays were based on the 3-[4,5-dimethythiazol-2-yl]-2,5-diphenyltetrazolium bromide (MTT) method. Cells were seeded in a 96-well plate, at a density of $1 \times 10^{4}$ cells/well. After overnight culture, PCAE was added to the cells and cultured for $24 \mathrm{~h}$. The medium was removed and DMSO was added at MTT solubilization solution. Absorbance was measured at $550 \mathrm{~nm}$.

Colony-forming assay. Single-cell suspensions of $5 \times 10^{3}$ cells were seeded in a 6-well plate and allowed to attach for $24 \mathrm{~h}$ at $37^{\circ} \mathrm{C}$ in culture medium. The cells were then treated with 100 or $1,000 \mu \mathrm{M}$ PCAE. After 10 days, the colonies were fixed with $100 \%$ methanol for $10 \mathrm{~min}$ at room temperature and stained with $0.1 \%$ crystal violet. Plates were washed with phosphate-buffered saline (PBS) and images were captured.

Immunofluorescence staining. MDA-MB231 cells were grown in 4-chamber slides in serum-free medium, and were treated with LPS $(5 \mu \mathrm{g} / \mathrm{ml})$ or co-treated with LPS $(5 \mu \mathrm{g} / \mathrm{ml})$ and PVAE $(100 \mu \mathrm{M})$. After $24-\mathrm{h}$ incubation, the cells were fixed with $4 \%$ paraformaldehyde at $4{ }^{\circ} \mathrm{C}$. The cells were washed with PBS containing 0.1\% BSA and incubated with anti-N-cadherin antibody for $1 \mathrm{~h}$ followed by $1 \mathrm{~h}$ incubation with fluorescence-tagged secondary antibody, then counterstained with 4',6-diamidino-2-phenylindole (DAPI) for $5 \mathrm{~min}$. Cell images were captured at a magnification of $x 400$ on a Leica fluorescence microscope.

Cell migration assay. Migration was assessed by a woundhealing assay. The cells were seeded at $2 \times 10^{4}$ MDA-MB231 and SKOV-3 cells/well and were cultured for $24 \mathrm{~h}$. After scraping the cell monolayer with a sterile micropipette tip, the wells were washed with PBS, and treated with LPS $(5 \mu \mathrm{g} / \mathrm{ml})$ or co-treated with LPS $(5 \mu \mathrm{g} / \mathrm{ml})$ and PCAE $(100 \mu \mathrm{M})$. The first image of each scratch was obtained at time zero. At $24 \mathrm{~h}$, each scratch was examined and captured at the same location and the healed area was measured.

Transwell invasion assay. The invasion of tumor cells was assessed in Transwell chambers equipped with $8-\mu \mathrm{m}$ pore size, $6.5 \mathrm{~mm}$ diameter polyvinylpyrrolidone-free polycarbonated membranes that were coated with $1 \mathrm{mg} / \mathrm{ml}$ fibronectin. The cells were seeded onto the upper wells at a concentration of $1 \times 10^{5}$ and MDA-MB231 and SKOV-3 cells/well were cultured for $24 \mathrm{~h}$ following treatment with LPS $(5 \mu \mathrm{g} / \mathrm{ml})$ or co-treatment with LPS $(5 \mu \mathrm{g} / \mathrm{ml})$ and PCAE $(100 \mu \mathrm{M})$. The bottom chambers of the Transwell were filled with conditioned medium. After incubation for $24 \mathrm{~h}$, the cells were fixed with $100 \%$ methanol for $10 \mathrm{~min}$ at room temperature, stained with $0.1 \%$ crystal violet and counted under a light microscope.

Western blotting. The MDA-MB231 and SKOV-3 cells were treated with LPS $(5 \mu \mathrm{g} / \mathrm{ml})$ or co-treated with LPS $(5 \mu \mathrm{g} / \mathrm{ml})$ and PVAE $(100 \mu \mathrm{M})$ for $24 \mathrm{~h}$. After lysing the cells with RIPA buffer, the proteins were resolved by SDS-PAGE and immunoblotted using primary antibodies such as anti-N-cadherin, anti- $\beta$-catenin, anti-vimentin, anti-NF- $\kappa \mathrm{B}$ p65 subunit, anti-Snail and anti- $\beta$-actin antibody. Following treatment with appropriate secondary antibodies, the immunoreactive bands were visualized using a standard ECL method.

Statistical analysis. The results are presented as mean \pm SE. Statistical comparisons between groups were carried out using one-way ANOVA followed by the Student's t-test.

\section{Results}

PCAE inhibits the growth of human cancer cell in vitro. We initially examined the effects of PCAE on the proliferation of two human metastatic cancer cell lines, MDA-MB231 (breast cancer cells) and SKOV-3 (ovarian cancer cells). The cancer cell lines were treated for $24 \mathrm{~h}$ with various concentrations of PCAE and cell viability was measured with a 3-(4,5-dimethylthiazol-2yl)-2,5-diphenyltetrazolium bromide (MTT) assay. As shown in Fig. 1A, cell proliferation was inhibited by PCAE in a dose-dependent manner, although a different $\mathrm{IC}_{50}$ (the drug concentration that causes $50 \%$ growth inhibition) was observed for each cell line $(417 \pm 7 \mu \mathrm{g} / \mathrm{ml}$ for MDA-MB231 and $690 \pm 4 \mu \mathrm{g} / \mathrm{ml}$ for SKOV-3). The long-term effects of PCAE were determined with a colony-forming assay. MDA-MB231 and SKOV-3 cells were cultured with or without PCAE for 10-15 days. A PCAE concentration of $100 \mu \mathrm{g} / \mathrm{ml}$ had no significant effect on the cells, whereas $1,000 \mu \mathrm{g} / \mathrm{ml}$ PCAE almost completely inhibited colony formation (Fig. 1B and C). Therefore, we considered $100 \mu \mathrm{g} / \mathrm{ml}$ PCAE a suitable dose for subsequent experiments.

PCAE inhibits LPS-induced cell migration and invasion during EMT. Chen et al have reported that, LPS $(5 \mu \mathrm{g} / \mathrm{ml})$ independently triggers the EMT process (12). We investigated the effects of PCAE on cell migration and invasion to verify that PCAE inhibits LPS-induced EMT since the EMT is associated with enhanced tumor progression. Two cancer cell lines were treated with LPS-alone, a combination of LPS plus PCAE or PCAE-alone, and were monitored with a wound-healing 
A

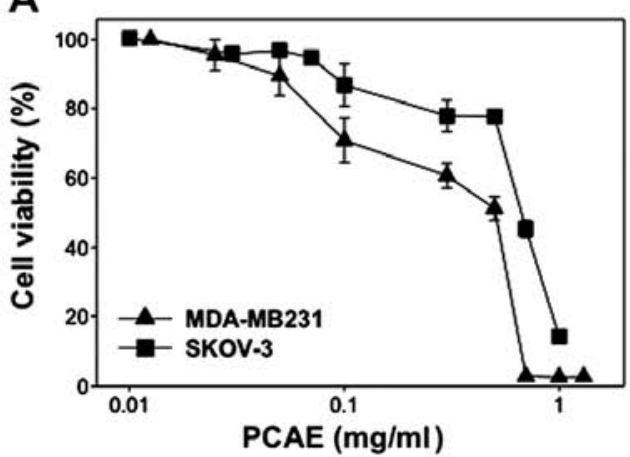

B

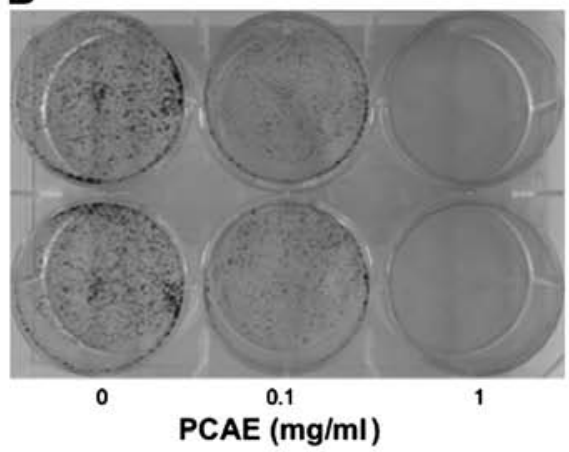

C

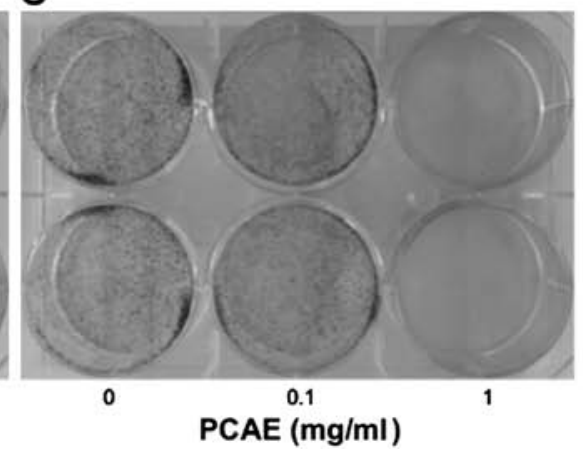

Figure 1. PCAE inhibits the growth of human cancer cells. (A) Antiproliferative effects of PCAE on MDA-MB231 and SKOV-3 cells after 24 h. Cell proliferation was determined with an MTT assay. The results are expressed as the means \pm SD of three replicate measurements from a single experiment, and are representative of three independent experiments. Inhibitory effects of PCAE on the colony formation of (B) MDA-MB231 and (C) SKOV-3 cells. Representative images of colony formation. PCAE, Psoralea corylifolia $\mathrm{L}$.

A
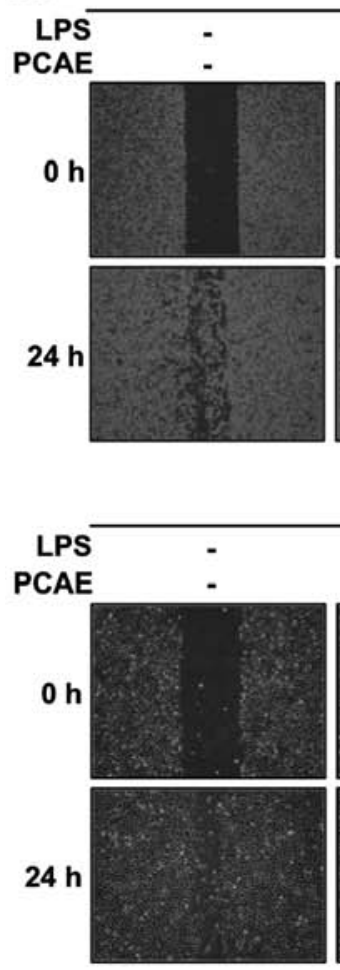

MDA-MB231
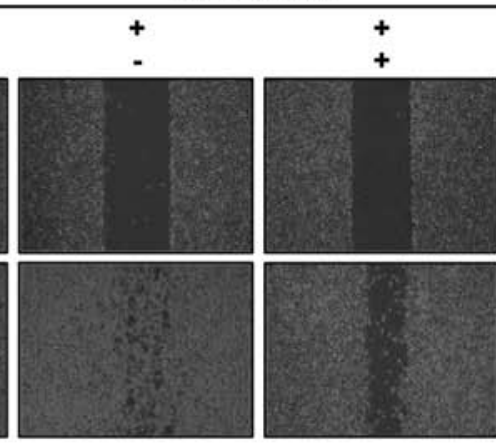

SKOV-3

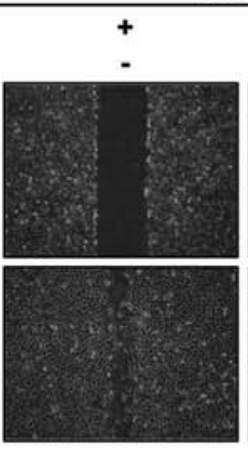

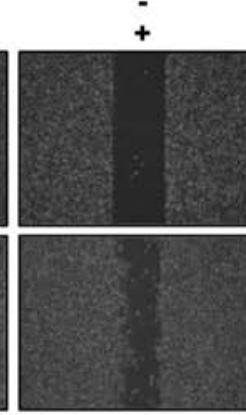

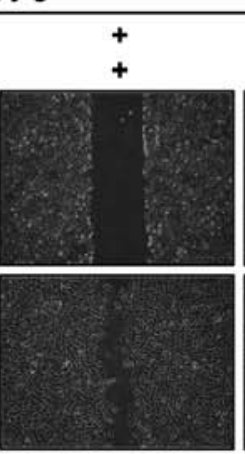

B
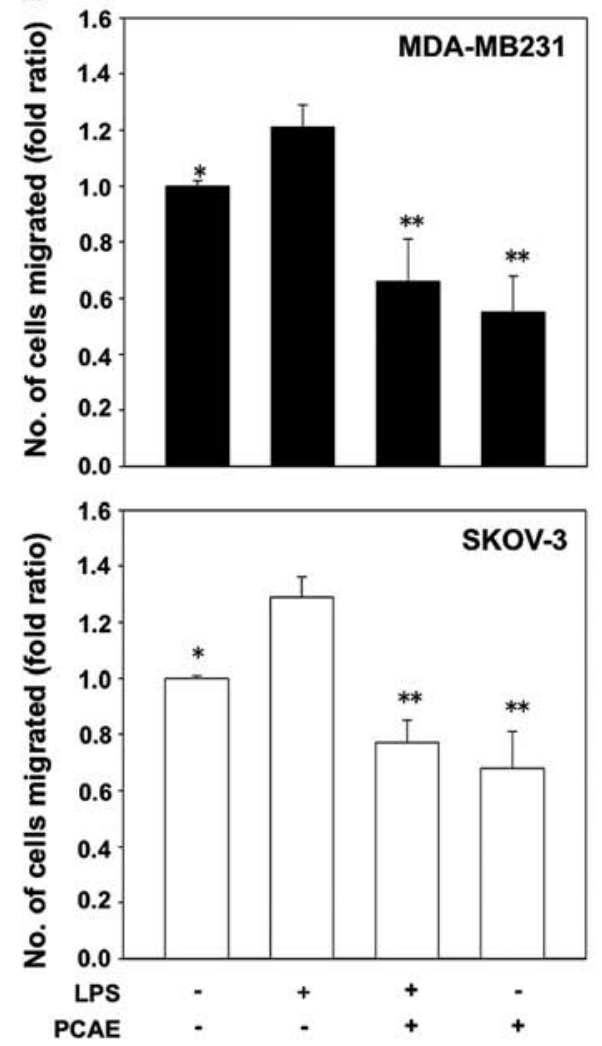

Figure 2. PCAE inhibits LPS-induced cell migration of MDA-MB231 and SKOV-3 cells. (A) Representative images of wound healing were captured at the time of scratching and $24 \mathrm{~h}$ thereafter. (B) Cell migration into the wounded area was quantified as the fold ratio of wound healing ( $\mathrm{n}=5$ ). ${ }^{*} \mathrm{P}<0.05,{ }^{* *} \mathrm{P}<0.01 \mathrm{vs}$. LPS-treated cells. PCAE, Psoralea corylifolia L.; LPS, lipopolysaccharide.

assay and a fibronectin-based Transwell invasion assay. The LPS-treated cancer cells exhibited a $\geq 1$. 2 -fold increase in migration, whereas treatment with $100 \mu \mathrm{g} / \mathrm{ml}$ PCAE inhibited this LPS-induced migration by $60 \%$ (Fig. 2A and B). We also examined whether PCAE inhibits the LPS-induced invasiveness of cancer cells. Following treatment with LPS-alone, the number of invasive cells significantly increased compared with the untreated cells ( $\geq 1$.6-fold increase). However, the number of invasive cells was significantly reduced in the cells treated with the combination of LPS plus PCAE (Fig. 3A and B). These data suggested that PCAE inhibited the effect of LPS, thus increasing the invasiveness of human cancer cells, as occurs for the EMT.

PCAE regulates the expression of EMT-related proteins in human cancer cells. We investigated the expression of EMT-related proteins, such as N-cadherin, $\beta$-catenin and vimentin, to clarify the effects of PCAE on the LPS-induced 
A

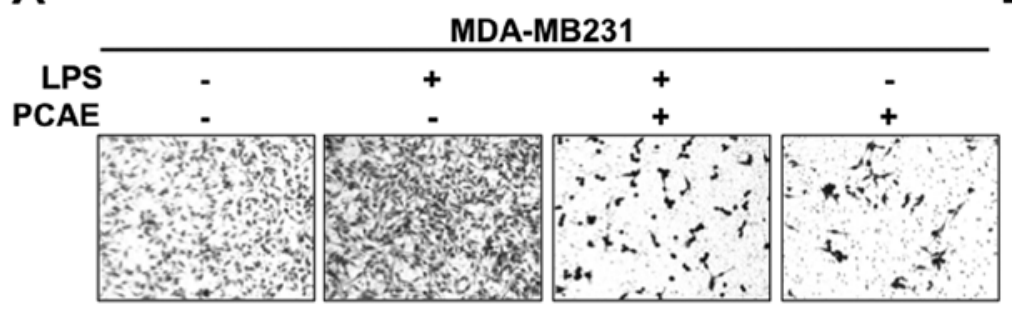

SKOV-3

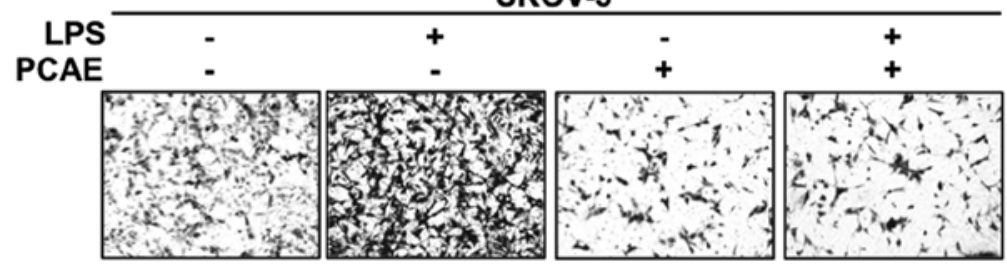

B
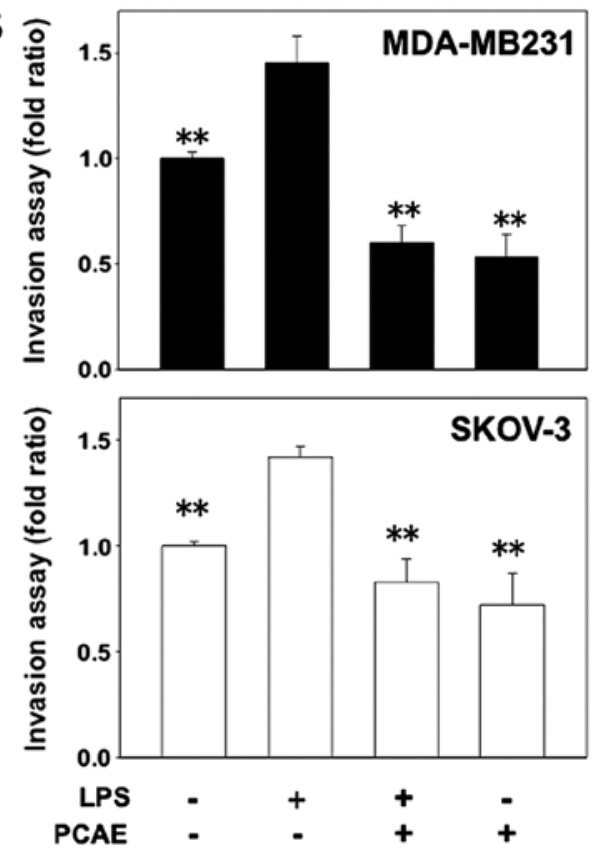

Figure 3. PCAE inhibits the cell invasion stimulated by LPS. (A) Cell invasion was determined with a Transwell assay. Representative photomicrographs of membrane-associated cells stained with crystal violet. (B) Cell invasion values were quantified as the fold ratio of invaded cells $(\mathrm{n}=5)$. ${ }^{*} \mathrm{P}<0.05$, ${ }^{* *} \mathrm{P}<0.01 \mathrm{vs}$. LPS-treated cells. PCAE, Psoralea corylifolia L.; LPS, lipopolysaccharide.

EMT. The protein expression was measured using western blotting and quantitatively analyzed (Fig. 4A and B). The expression of $\beta$-catenin was significantly downregulated, whereas that of $\mathrm{N}$-cadherin and vimentin was upregulated in the LPS-treated cancer cells compared with their expression in the controls. However, PCAE reversed the LPS-induced EMT by reinducing the expression of $\beta$-catenin, and inhibiting $\mathrm{N}$-cadherin and vimentin expression. We also examined the expression of $\mathrm{N}$-cadherin in cancer cells with fluorescent imaging (Fig. 4C). Consistent with the western blotting results, $\mathrm{N}$-cadherin was highly expressed after LPS treatment, although its expression decreased significantly after PCAE treatment. The western blotting and fluorescent imaging results suggested that PCAE inhibits the cellular EMT.

$N F-\kappa B-S N A I L$ signaling is required to alter EMT marker expression. Previous findings showed numerous drugs inhibit the invasion and migration of cancer cells by suppressing $N F-\kappa B$ expression $(13,14)$. Therefore, the NF- $\kappa \mathrm{B}$ signaling pathway is critically involved in the acquisition of the EMT, mediated by SNAIL, a transcription factor directly downstream from $N F-\kappa B$. To determine whether the effect of PCAE described above is associated with the inhibition of the NF- $\kappa$ B-SNAIL pathway, we investigated the expression of the NF- $\kappa$ B p65 subunit and SNAIL protein using western blotting and quantitative analysis (Fig. 5A and B). As shown in Fig. 5, LPS significantly upregulated the expression of NF- $\kappa \mathrm{B}$ p65 and SNAIL protein, with the exception of $\mathrm{NF}-\kappa \mathrm{B}$ p65 in MDA-MB231, which reduced the expression of E-cadherin and $\beta$-catenin, and increased the expression of $\mathrm{N}$-cadherin and vimentin as identified in previous western blotting results. However, PCAE inhibited this effect, counteracting the effect of LPS on NF- $\mathrm{B}$ p 65 and SNAIL expression. PCAE even decreased NF- $\mathrm{B}$ p 65 and SNAIL expression compared to the control group. These results indicated that PCAE inhibits the activation of NF- $\kappa B-S N A I L$, which plays a critical role in the EMT.

\section{Discussion}

The EMT is the best-known example of the changes that occur in the patterns and functions of cancer cells (15). Epithelial cells acquire mesenchymal fibroblast-like phenotypes, with reduced cell-cell adhesion, loss of polarity and increased migration and invasiveness (16). As a prerequisite for EMT, cells lose their cell-cell junctions via different mechanisms, including loss-of-function mutations in the cadherins or catenins, or the upregulation of proteases that cleave the cadherins (17). The EMT is considered to be a significant step in the invasive cascade, facilitating the migration of tumor cells from their site of origin and their dissemination to distant tissues (18). When the tumor reaches the dedifferentiated stage, at which single cells are disseminated, metastatic spread increases, resulting in a poor prognosis. Therefore, blocking or reversing this process with exogenous agents is a promising therapeutic strategy to limit cancer spread.

In a previous study, LPS induced the EMT of cancer cells, increasing their invasiveness and migration, which enhanced the metastasis of breast cancer cells to the lung (19). In the present study, we have shown that various cancer cells can be induced by LPS to undergo a stimulated EMT, reducing $\beta$-catenin expression, and increasing $\mathrm{N}$-cadherin and vimentin expression. PCAE inhibits the action of LPS in inducing EMT, reversing the altered expression of proteins associated with cell invasion and migration. We also found that NF- $\kappa$ B-SNAIL signaling is required for the LPS-induced EMT in various 
A

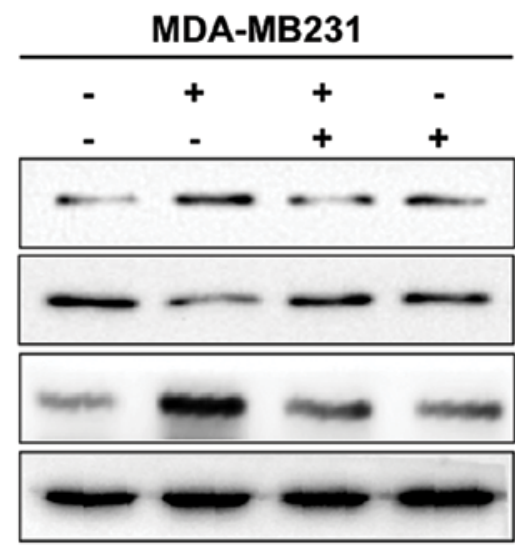

B

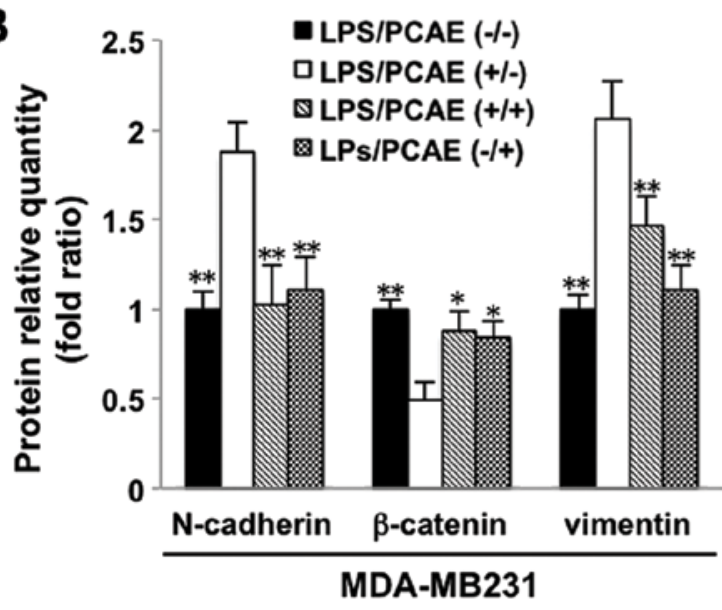

C

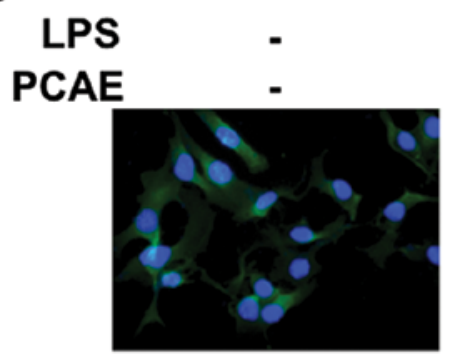

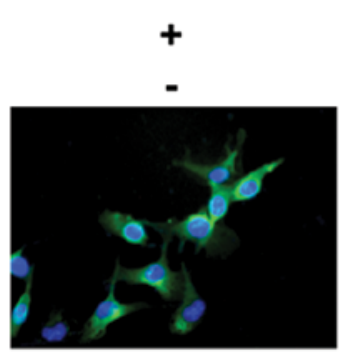

SKOV-3
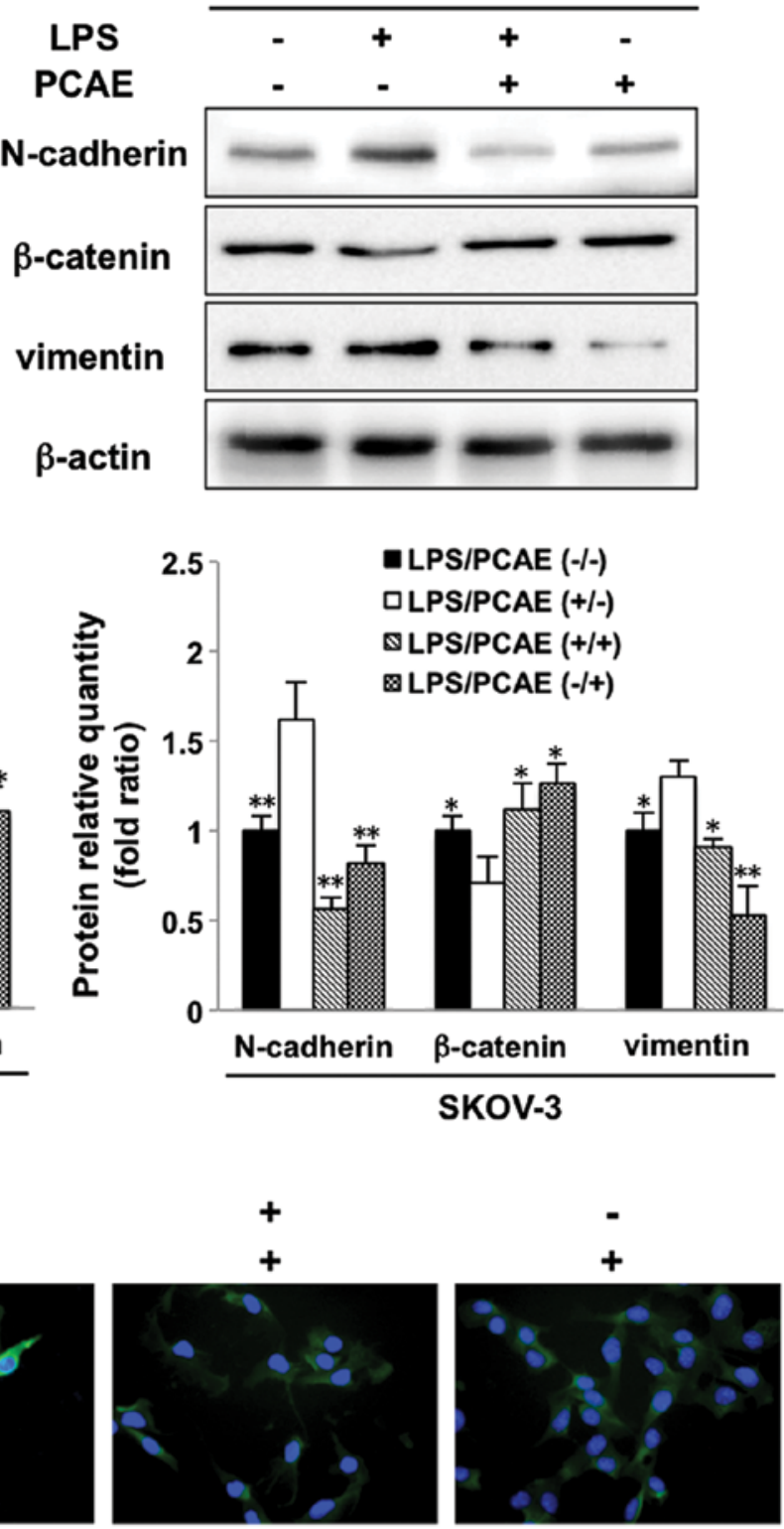

Figure 4. PCAE regulates the expression of EMT-related proteins. (A) Expression of E-cadherin, $\beta$-catenin, $N$-cadherin and vimentin proteins in MDA-MB231 and SKOV-3 cells was determined with western blotting. (B) Protein relative expression from western blotting was quantified as the fold ratio ( $\mathrm{n}=3$ ). ${ }^{*} \mathrm{P}<0.05$ and ${ }^{* *} \mathrm{P}<0.01$ vs. LPS-treated cells. (C) MDA-MB231 cells were immunostained with anti-N-cadherin antibody and the nuclei were counterstained with 4',6-diamidino-2-phenylindole (DAPI) after PCAE treatment. PCAE, Psoralea corylifolia L.; LPS, lipopolysaccharide.

cancer cells, which clarifies the mechanism by which PCAE inhibits cancer cell metastasis.

PC has been widely used in Ayurvedic and Chinese medicine as a cardiac tonic, vasodilator and antitumor, antibacterial, cytotoxic and antihelminthic agent (8). Extracts of PC produced with various solvents, such as methanol, ethanol and chloroform, have significant antitumor activity since they inhibit DNA replication, the induction of hypoxia-inducible factor-1 activation by hypoxia, mitochondrial complex I and proteasomal activities $(11,20,21)$. However, PC has not been associated with cancer metastasis via the EMT, although its strong antitumor effects have been reported. To the best of our knowledge, this is the first study to demonstrate that the antimetastatic effects of PC are associated with the EMT in cultured human cancer cells. Therefore, our results suggest a new dietary chemopreventive role for PC in inhibiting the progression of cancer metastasis.

In the present study, we have shown that PCAE inhibits the LPS-induced EMT, and thus cell migration and invasion, which result from the dysregulation of cell-cell adhesion proteins and the expression of EMT-related proteins, such as $\mathrm{N}$-cadherin. Cadherins are transmembrane glycoproteins that mediate $\mathrm{Ca}^{2+}$-dependent cell-cell adhesion (22). N-cadherin is associated with the heightened invasive potential of cancer cells. N-cadherin is typically expressed by mesenchymal cells, is overexpressed in some cancer cells and correlates with cell invasiveness (23). Therefore, the gain of $\mathrm{N}$-cadherin expression in cancer cells has a functional significance in cancer progression and metastasis (24). PCAE also regulates the expression of other EMT-related proteins, such as $\beta$-catenin 
A

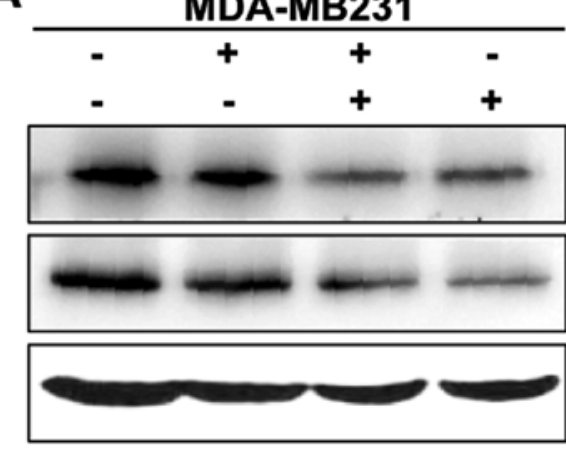

B

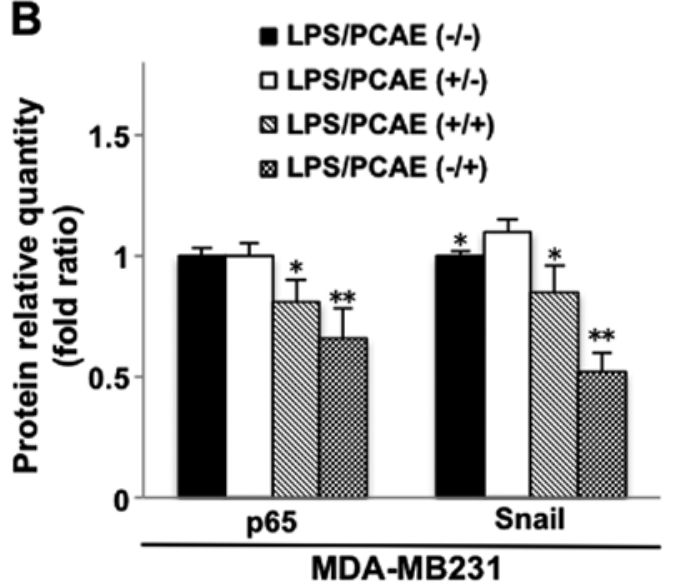

SKOV-3
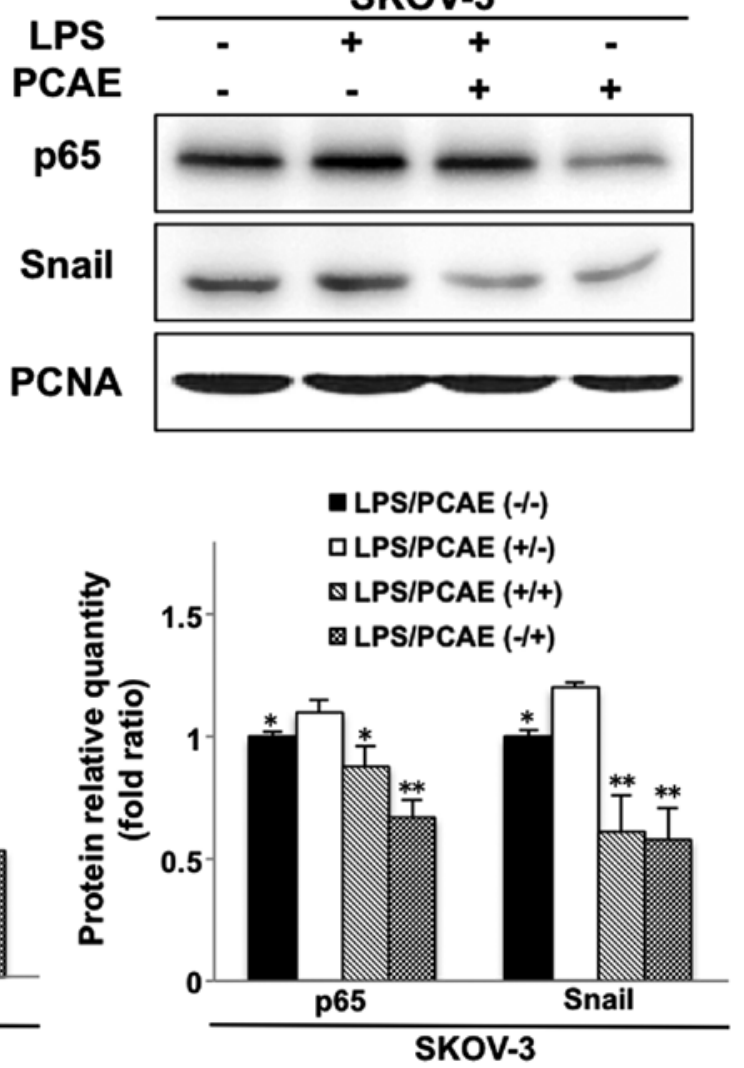

Figure 5. Activation of NF- $\kappa$ B-SNAIL signaling is inhibited by PCAE. Western blot analysis of the expression of the NF- $\kappa$ B p65 subunit and SNAIL protein in MDA-MB231 and SKOV-3 cells following treatment with PCAE for $24 \mathrm{~h}$. (B) Protein relative expression from western blotting was quantified as the fold ratio $(\mathrm{n}=3)$. ${ }^{*} \mathrm{P}<0.05,{ }^{* *} \mathrm{P}<0.01$ vs. LPS-treated cells. PCAE, Psoralea corylifolia $\mathrm{L}$.; LPS, lipopolysaccharide.

and vimentin, inhibiting cell migration and invasion. $\beta$-catenin is a transcription factor in the WNT signaling pathway and is involved in the regulation of cell adhesion. It is typically most abundant in epithelial-like cells $(25,26)$. Vimentin is an intermediate filament typically found in non-epithelial and mesenchymal cells (27). When drugs inhibit the EMT of cancer cells, $\beta$-catenin expression increases and vimentin expression decreases.

Our results suggest that the mechanism of action of Psoralea corylifolia L. involves the suppression of $\mathrm{NF}-\kappa \mathrm{B}-\mathrm{SNAIL}$ signaling. NF- $\mathrm{B}$ is a structurally conserved family of dimeric transcription factors that play pivotal roles in maintaining the invasive phenotype and promoting the metastasis of cancer cells (28-30). It is also an essential central mediator of the EMT since the SNAIL transcription factor plays a critical role in the EMT and its expression is directly induced by $N F-\kappa B(31)$. The expression of SNAIL mRNA at the EMT may be reversed by the inhibition of $N F-\kappa B$, which is the upstream regulator of SNAIL expression at the EMT (32). Our results support previous findings that NF- $\kappa \mathrm{B}$ is the upstream regulator of SNAIL and indirectly mediates the EMT, explaining the inhibition of tumor progression by Psoralea corylifolia $\mathrm{L}$. and PCAE.

In conclusion, we have shown that PCAE inhibits tumor cell invasion and migration, which are associated with the EMT during tumor progression, possibly by inhibiting the activation of NF- $\kappa \mathrm{B}-\mathrm{SNAIL}$ signaling and regulating the expression of important downstream EMT markers, such as E-cadherin, $\beta$-catenin, $\mathrm{N}$-cadherin and vimentin. Although further in vivo studies are required to determine the potential utility of PCAE, inhibiting the migration and invasion of tumor cells, as a cancer therapy, we suggest that PCAE is an effective dietary chemopreventive agent for malignant tumors because it inhibits metastasis.

\section{Acknowledgements}

The present study was supported by the Traditional Korean Medicine R\&D Program funded by the Ministry of Health and Welfare through the Korea Health Industry Development Institute (HI14C05830000), and by the Basic Science Research Program through the National Research Foundation of Korea (NRF) funded by the Ministry of Education (2014R1A1A2057861).

\section{References}

1. Jemal A, Bray F, Center MM, Ferlay J, Ward E and Forman D: Global cancer statistics. CA Cancer J Clin 61: 69-90, 2011.

2. Sleeman JP, Nazarenko I and Thiele W: Do all roads lead to Rome? Routes to metastasis development. Int J Cancer 128: 2511-2526, 2011.

3. Steeg PS: Tumor metastasis: Mechanistic insights and clinical challenges. Nat Med 12: 895-904, 2006.

4. Collado M and Serrano M: Senescence in tumours: Evidence from mice and humans. Nat Rev Cancer 10: 51-57, 2010. 
5. Klein CA: Parallel progression of primary tumours and metastases. Nat Rev Cancer 9: 302-312, 2009.

6. Gupta GP, Minn AJ, Kang Y, Siegel PM, Serganova I, CordónCardo C, Olshen AB, Gerald WL and Massagué J: Identifying site-specific metastasis genes and functions. Cold Spring Harb Symp Quant Biol 70: 149-158, 2005.

7. Minn AJ, Gupta GP, Siegel PM, Bos PD, Shu W, Giri DD, Viale A, Olshen AB, Gerald WL and Massagué J: Genes that mediate breast cancer metastasis to lung. Nature 436: 518-524, 2005.

8. Chopra B, Dhingra AK and Dhar KL: Psoralea corylifolia L. (Buguchi) - folklore to modern evidence: Review. Fitoterapia 90: 44-56, 2013.

9. Wang Y, Hong C, Zhou C, Xu D and Qu HB: Screening antitumor compounds psoralen and isopsoralen from Psoralea corylifolia L. seeds. Evid Based Complement Alternat Med 2011: 363052, 2011.

10. Latha PG, Evans DA, Panikkar KR and Jayavardhanan KK: Immunomodulatory and antitumour properties of Psoralea corylifolia seeds. Fitoterapia 71: 223-231, 2000.

11. Tang SY, Gruber J, Wong KP and Halliwell B: Psoralea corylifolia $\mathrm{L}$. inhibits mitochondrial complex I and proteasome activities in SH-SY5Y cells. Ann NY Acad Sci 1100: 486-496, 2007.

12. Chen MC, Chang WW, Kuan YD, Lin ST, Hsu HC and Lee CH Resveratrol inhibits LPS-induced epithelial-mesenchymal transition in mouse melanoma model. Innate Immun 18: 685-693, 2012.

13. Kim A, Im M and Ma JY: Anisi stellati fructus extract attenuates the in vitro and in vivo metastatic and angiogenic potential of malignant cancer cells by downregulating proteolytic activity and pro-angiogenic factors. Int J Oncol 45: 1937-1948, 2014.

14. Liu YC, Chiang IT, Hsu FT and Hwang JJ: Using NF- $\kappa$ B as a molecular target for theranostics in radiation oncology research. Expert Rev Mol Diagn 12: 139-146, 2012.

15. Friedl $\mathrm{P}$ and Wolf K: Tumour-cell invasion and migration: Diversity and escape mechanisms. Nat Rev Cancer 3: 362-374, 2003.

16. De Craene B and Berx G: Regulatory networks defining EMT during cancer initiation and progression. Nat Rev Cancer 13: 97-110, 2013

17. Thiery JP: Epithelial-mesenchymal transitions in tumour progression. Nat Rev Cancer 2: 442-454, 2002.

18. Mulholland DJ, Kobayashi N, Ruscetti M, Zhi A, Tran LM Huang J, Gleave $\mathrm{M}$ and $\mathrm{Wu} \mathrm{H}$ : Pten loss and RAS/MAPK activation cooperate to promote EMT and metastasis initiated from prostate cancer stem/progenitor cells. Cancer Res 72: 1878-1889, 2012.

19. Wu Y, Deng J, Rychahou PG, Qiu S, Evers BM and Zhou BP. Stabilization of snail by NF-kappaB is required for inflammationinduced cell migration and invasion. Cancer Cell 15: 416-428, 2009.
20. Whelan LC and Ryan MF: Ethanolic extracts of Euphorbia and other ethnobotanical species as inhibitors of human tumour cell growth. Phytomedicine 10: 53-58, 2003.

21. Wu CZ, Cai XF, Dat NT, Hong SS, Han AR, Seo EK, Hwang BY, Nan JX, Lee D and Lee JJ: Bisbakuchiols A and B, novel dimeric meroterpenoids from Psoralea corylifolia. Tetrahedron Lett 48 8861-8864, 2007.

22. van Roy F and Berx G: The cell-cell adhesion molecule E-cadherin. Cell Mol Life Sci 65: 3756-3788, 2008.

23. Nguyen PT, Kudo Y, Yoshida M, Kamata N, Ogawa I and Takata T: $\mathrm{N}$-cadherin expression is involved in malignant behavior of head and neck cancer in relation to epithelial-mesenchymal transition. Histol Histopathol 26: 147-156, 2011.

24. Araki K, Shimura T, Suzuki H, Tsutsumi S, Wada W, Yajima T, Kobayahi T, Kubo N and Kuwano $\mathrm{H}$ : E/N-cadherin switch mediates cancer progression via TGF- $\beta$-induced epithelial-tomesenchymal transition in extrahepatic cholangiocarcinoma. $\mathrm{Br}$ J Cancer 105: 1885-1893, 2011.

25. Huang J, Xiao D, Li G, Ma J, Chen P, Yuan W, Hou F, Ge J, Zhong M, Tang Y, et al: EphA2 promotes epithelial-mesenchymal transition through the $\mathrm{Wnt} / \beta$-catenin pathway in gastric cancer cells. Oncogene 33: 2737-2747, 2014.

26. Yan D, Avtanski D, Saxena NK and Sharma D: Leptin-induced epithelial-mesenchymal transition in breast cancer cells requires $\beta$-catenin activation via Akt/GSK3- and MTA1/Wnt1 proteindependent pathways. J Biol Chem 287: 8598-8612, 2012.

27. Liu Z, Chen L, Zhang X, Xu X, Xing H, Zhang Y, Li W, Yu H, Zeng $J$ and Jia J: RUNX3 regulates vimentin expression via miR-30a during epithelial-mesenchymal transition in gastric cancer cells. J Cell Mol Med 18: 610-623, 2014.

28. Wu K, Zeng J, Li L, Fan J, Zhang D, Xue Y, Zhu G, Yang L, Wang X and He D: Silibinin reverses epithelial-to-mesenchymal transition in metastatic prostate cancer cells by targeting transcription factors. Oncol Rep 23: 1545-1552, 2010.

29. Xiao LJ, Chen YY, Lin P, Zou HF, Lin F, Zhao LN, Li D, Guo L, Tang JB, Zheng XL, et al: Hypoxia increases CX3CR1 expression via HIF-1 and NF- $\kappa \mathrm{B}$ in androgen-independent prostate cancer cells. Int J Oncol 41: 1827-1836, 2012.

30. Ennen M, Klotz R, Touche N, Pinel S, Barbieux C, Besancenot V, Brunner E, Thiebaut D, Jung AC, Ledrappier S, et al: DDB2: A novel regulator of $\mathrm{NF}-\kappa \mathrm{B}$ and breast tumor invasion. Cancer Res 73: 5040-5052, 2013.

31. Chua HL, Bhat-Nakshatri P, Clare SE, Morimiya A, Badve S and Nakshatri H: NF-kappaB represses E-cadherin expression and enhances epithelial to mesenchymal transition of mammary epithelial cells: Potential involvement of ZEB-1 and ZEB-2. Oncogene 26: 711-724, 2007.

32. Min C, Eddy SF, Sherr DH and Sonenshein GE: NF-kappaB and epithelial to mesenchymal transition of cancer. J Cell Biochem 104: 733-744, 2008 